\title{
Anti-ischemic therapy and stress testing: pathophysiologic, diagnostic and prognostic implications Rosa Sicari*
}

\author{
Address: CNR, Institute of Clinical Physiology, Pisa, Italy \\ Email: Rosa Sicari* - rosas@ifc.cnr.it \\ * Corresponding author
}

Published: 20 August 2004

Cardiovascular Ultrasound 2004, 2:14 doi:10.1 |86/1476-7|20-2-14
Received: 01 June 2004

Accepted: 20 August 2004

This article is available from: http://www.cardiovascularultrasound.com/content/2/I//4

(C) 2004 Sicari; licensee BioMed Central Ltd.

This is an open-access article distributed under the terms of the Creative Commons Attribution License (http://creativecommons.org/licenses/by/2.0), which permits unrestricted use, distribution, and reproduction in any medium, provided the original work is properly cited.

\begin{abstract}
Anti-ischemic therapy, in particular beta-blockers, is the most commonly employed drug for the control of myocardial ischemia in patients with stable coronary artery disease. Its widespread use also in patients with suspected coronary artery disease has important practical, clinical diagnostic and prognostic implications because diagnostic tests are heavily influenced by its effects. In the present review, the pathophysiological mechanisms of ischemia protection by antianginal therapy are described. Not all stressors are created equal in front of the different classes of antianginal drugs and on their turn the different classes of drugs exert different levels of protection on inducible ischemia. Several clinical implications can be drawn: From the diagnostic viewpoint antianginal therapy decreases test sensitivity, offsetting the real ischemic burden for a too high percentage of false negative tests. From the prognostic viewpoint test positivity in medical therapy identifies a group of subjects at higher risk of experiencing cardiac death and positivity on medical therapy can be considered a parameter of ischemia severity. Nonetheless in patients with known coronary artery disease the ability of antianginal therapy to modify the ischemic threshold at stress testing represent a powerful means to assess therapy efficacy. From a practical viewpoint, the use of antianginal therapy at time of testing has advantages and disadvantages which are largely dependent on the purpose a test is performed: if the purpose of testing is to diagnose ischemia, it should be performed in the absence of antianginal medications. If the purpose of testing is to assess the protective effects of antianginal therapy, the test should be performed on medications.
\end{abstract}

\section{Background}

Anti-ischemic therapy, in particular beta-blockers, is the most commonly employed drug for the control of myocardial ischemia in patients with stable coronary artery disease. Its widespread use also in patients with suspected coronary artery disease has important practical, clinical diagnostic and prognostic implications because diagnostic tests are heavily influenced by its effects. The diagnostic and prognostic impact of anti-ischemic therapy on stress testing is largely ignored but not negligible. The issue raises several questions: How to evaluate patients at time of testing for myocardial ischemia? How to interpret a stress test performed on anti-ischemic therapy? Are the stressors employed for the detection of myocardial ischemia created equal in relation to the different classes of drugs used in clinical practice? Is stress testing able to assess the efficacy of medical therapy in patients with known coronary artery disease? Has the protection of antiischemic therapy on inducible myocardial ischemia any impact on long-term survival? 


\section{Pathophysiologic implications of anti-ischemic therapy during stress testing}

The answer to all these issues relies on the mechanism through which myocardial ischemia is induced by the different stressors (exercise or pharmacologic such as dipyridamole and dobutamine) employed during stress testing. Test exploring organic coronary artery stenosis can induce ischemia by two basic mechanisms: 1 . an increase in oxygen demand, exceeding the fixed supply and 2. flow maldistribution due to inappropriate coronary arteriolar triggered by a metabolic/pharmacologic stimulus [1]. The mechanism of increased demand can be easily fitted into the familiar concept framework of ischemia as a supplydemand mismatch, deriving from an increase in oxygen requirements in the presence of a fixed reduction in coronary flow reserve. The different stresses can determine increases in demand through different mechanisms (Fig. 1 ). In resting conditions, myocardial oxygen consumption is dependent mainly upon heart rate, inotropic state, and the left ventricular wall stress (which is proportional to the systolic blood pressure) [2]. Following dipyridamole or adenosine administration, a slight increase in myocardial function, a modest decrease in blood pressure, and mild tachycardia can be observed, overall determining only a trivial increase in myocardial oxygen demand [3]. During exercise, the increase in heart rate, blood pressure, and inotropic state accounts for the overall increase in myocardial oxygen consumption [4]. Pacing and dobutamine also increase - to a lesser degree - myocardial oxygen demand [5]. During pacing, the increase is mainly due to the increased heart rate. Dobutamine markedly increases contractility and heart rate. Further augment in myocardial oxygen consumption for heart rate increase occurs with the co-administration of atropine with dobutamine [6]. and dipyridamole [7]. (Fig. 2).

In the presence of coronary atherosclerosis, appropriate arteriolar dilation can paradoxically exert detrimental effects on regional myocardial perfusion, causing overperfusion of myocardial layers or regions already well perfused in resting conditions at the expense of regions or layers with a precarious flow balance in resting conditions [8]. Anti-ischemic therapy can interfere with all the above mentioned mechanisms of ischemia induction, although in a very different fashion. The mechanism of action of anti-ischemic drugs is easily fitted within the familiar framework of supply-demand mismatch. In particular, beta-blockers are credited with reducing exercise-induced ischemia by decreasing myocardial oxygen demand and possibly by increasing supply through a reduction in extravascular forces [9]. Experimental studies demonstrated that beta-blockers reduce dipyridamoleinduced ischemia by an alteration of regional myocardial blood flow [10]. However, this straightforward explanation seems inadequate in justifying the protective effects of beta-blockers on dipyridamole-induced ischemia. Experimental data show that beta-blockers do not affect the dipyiridamole-induced increase in flow [12]. On the other hand, the increase in myocardial oxygen consumption does not play any significant role in the induction of dipyridamole-induced ischemia, which is due to an absolute reduction in subendocardial flow (tightly linked to regional wall thickening) mostly for "vertical" and "horizontal" steal phenomena.

However, experimental studies on the model of the exercising dog have shown that beta-blockers protect myocardium from stress-induced myocardial blood flowfunction relation: for a given transmural flow, there is a rise of subendocardial and a fall of subepicardial flow, with an improved regional performance [10]. This same mechanism has also been documented with some calcium antagonists, such as diltiazem and may explain, in part, the beneficial effects of this class of drugs on dipyridamole-induced ischemia. Calcium antagonists can effectively prevent ischemia provoked by dipyridamole also through other mechanisms, which they share with nitrates, and they tend to increase the coronary flow supply during stress. In this case, the prevention of steal phenomena may be due to the increase in collateral flow (which has been shown with nitrates and, to a much lesser extent, with some calcium antagonists) [12]. and to the dilation of epicardial coronary lumen size. The pronounced increase in collateral flow can prevent horizontal steal phenomena due to dipyridamole, wheras even a small increase of the coronary diameter can dramatically reduce the blood pressure drop across the stenosis, therefore preventing vertical steal phenomena. Beta-blockers exert a direct and competitive action on beta-1 receptors, as they are employed as specific antagonists of dobutamine-induced ischemia. Dobutamine, through its beta- 1 agonist action determines the increase in oxygen consumption, but it induces flow maldistribution through beta- 2 arteriolar receptors.

\section{Diagnostic implications of the use of anti- ischemic therapy during stress testing}

On the basis of these premises and taking into consideration that the markers of inducible myocardial ischemia (electrocardiogram, perfusion, wall motion) are very different therefore expressing a different sensitivity to the action of anti-ischemic therapy at time of testing, it is clear that medical therapy affects test results (see table 1 . In fact, the AHA/ACC Guidelines on Chronic stable angina state that [13]. "whenever possible, it is recommended that beta-blockers (and other anti-ischemic drugs) be withheld for four to five half-lives (usually about $48 \mathrm{~h}$ ) before exercise imaging studies for the diagnosis and initial risk stratification of patients with suspected CAD". Ideally, these drugs should be withdrawn gradually to avoid a 


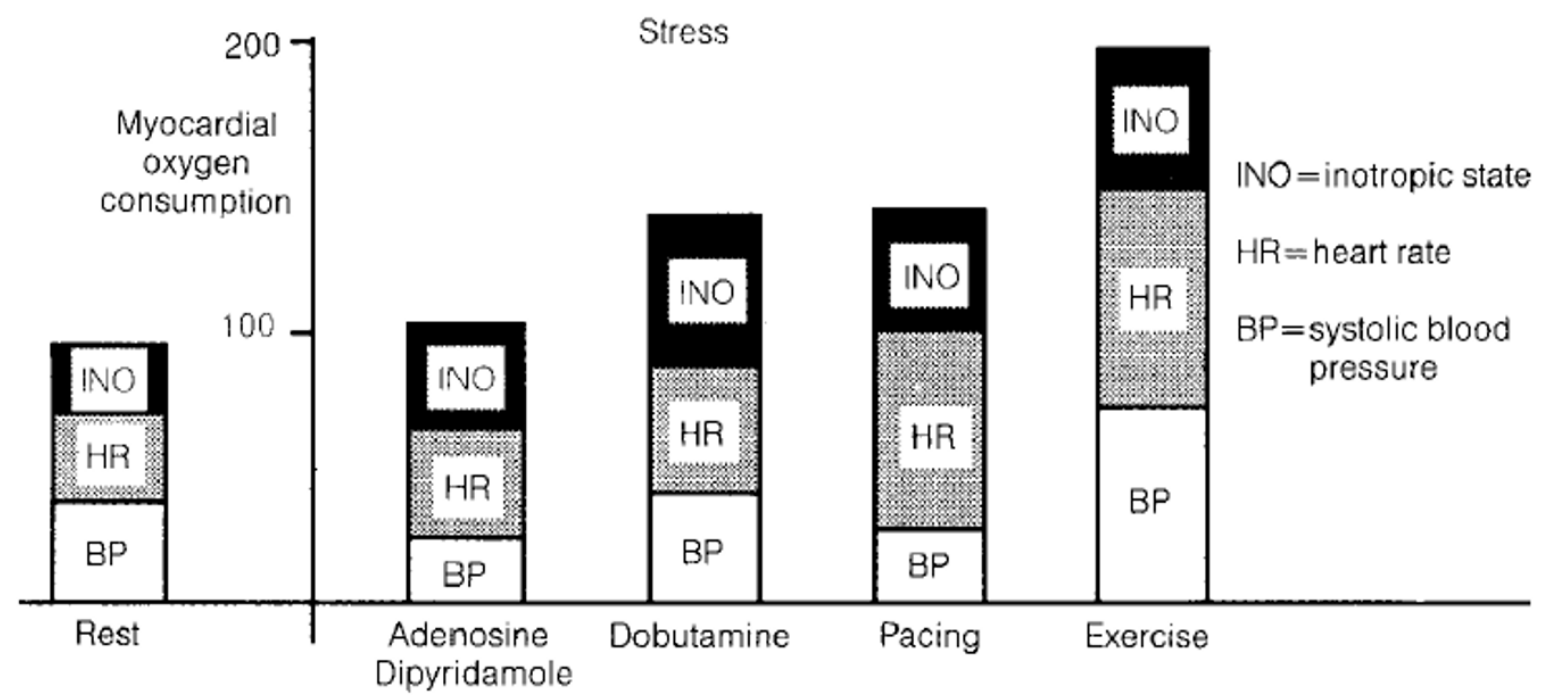

Figure I

Major determinants of myocardial oxygen consumption in resting conditions (left) and during stress commonly employed with echocardiography.

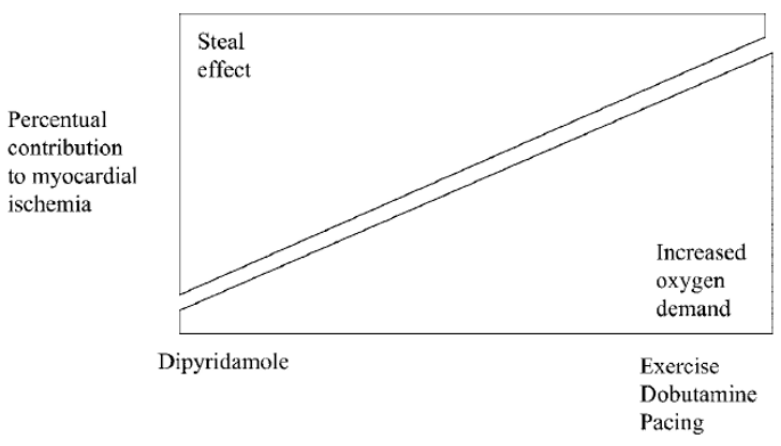

Figure 2

Conceptual allocation of tests employed in combination with echocardiography to detect coronary artery disease stenosis inducing ischemia via steal effect (left) or increased myocardial oxygen demand (right), or both mechanisms.

withdrawal phenomenon that may precipitate events. When beta-blockers cannot be stopped, stress testing may detect myocardial ischemia less reliably, but it usually will still be positive in patients at the highest risk. The same recommendations apply to imaging stress testing. Nonetheless, in patients who exercise to a submaximal level because of the effect of drugs, perfusion or echocardio-

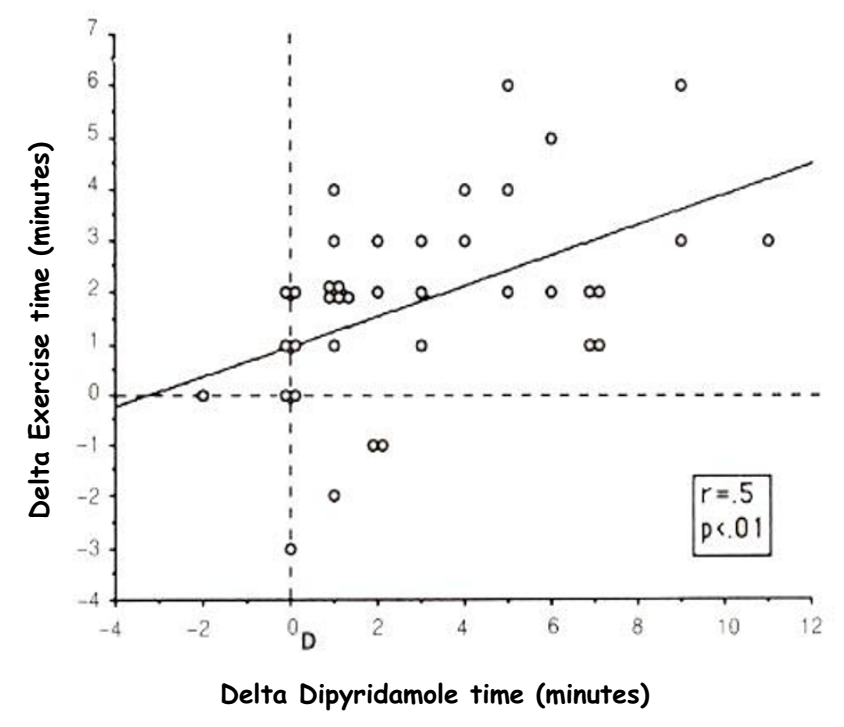

Figure 3

Correlation between the therapy-induced variations in dipyridamole and exercise time in the 38 patients with positivity of both tests off treatment (Modified from 2I).

graphic imaging still affords higher sensitivity than the exercise ECG alone [14]. On the basis of these recommen- 


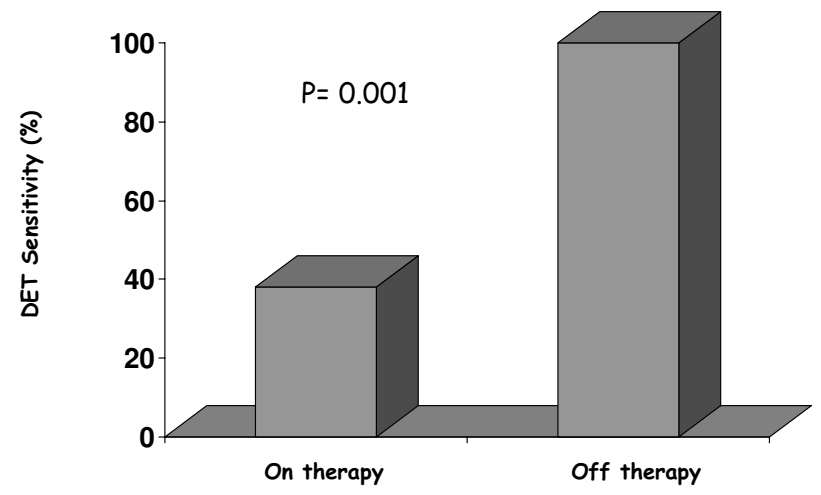

Figure 4

Dipyridamole test sensitivity on and off beta-blocking therapy (Modified from 23). Test sensitivity is significantly reduced in patients studied on beta-blocking therapy.

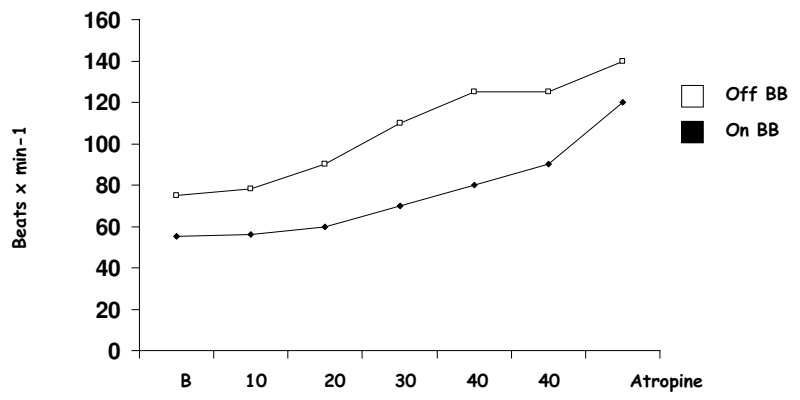

Figure 5

Heart rate during dobutamine-atropine stress testing on and off beta-blockers (Modified from 25).

dations patients undergoing a stress testing for diagnostic purposes should be evaluated off therapy not to offset test results. Exercise imaging stress (nuclear perfusion or ultrasound) testing have a lower sensitivity when performed on anti-ischemic therapy [14-19]. due to the limited increase in heart rate and blood pressure which determine oxygen consumption. Antianginal therapy lowers the sensitivity of exercise echocardiography as it does with vasodilator stress testing $[19,20]$. Antianginal therapy with beta-blockers, calcium-antagonists or nitrates in various combinations prevent dipyridamole-induced ischemia by delaying the appearance of the transient dyssynergy [21]. this variation on dipyridamole time parallels variations in exercise time at exercise stress testing [21]. (Fig. 3). Dipyridamole stress sensitivity was $91 \%$ off therapy and fell to $65 \%$ under therapy in various combina-

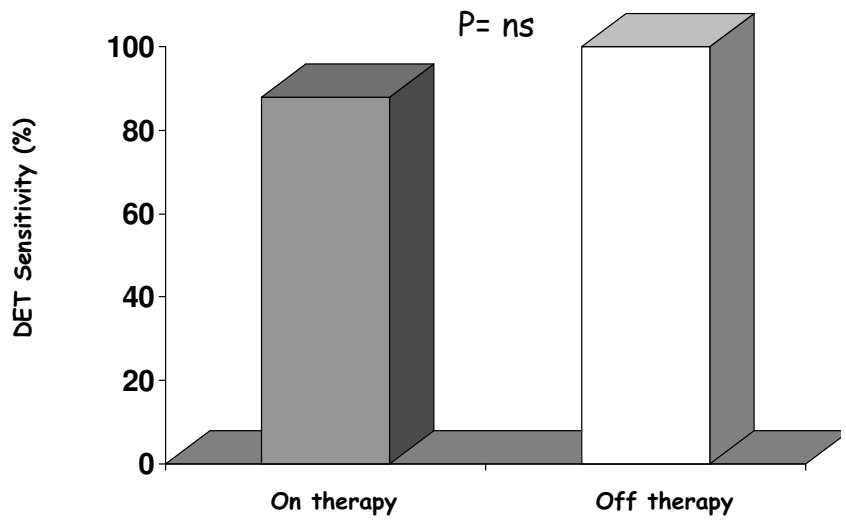

\section{Figure 6}

Dobutamine-atropine stress echocardiography test sensitivity in patients on and off non-beta blocking therapy (Modified from 26).

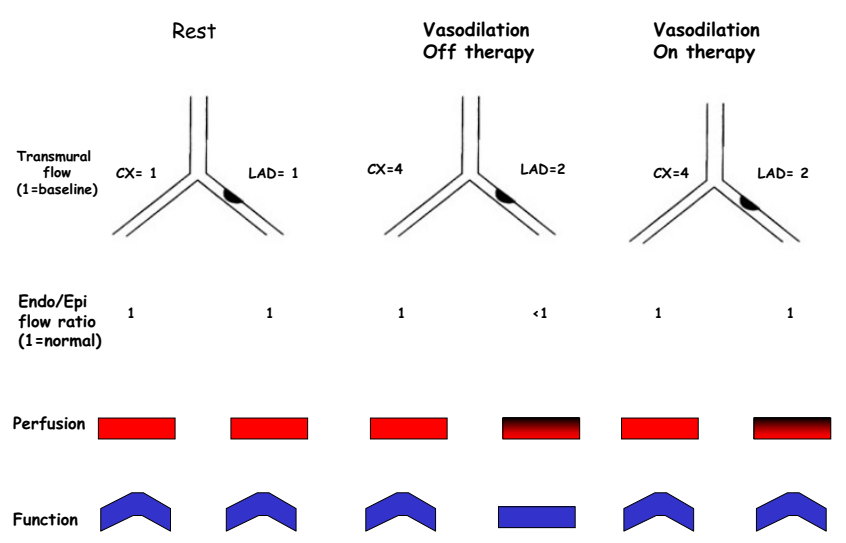

Figure 7

Schematic illustration of the principle underlying the impact of antianginal therapy on different markers of ischemia: regional function and perfusion imaging. At rest, perfusion is homogeneously distributed between endocardial and epicardial layers. In the presence of a significant coronary stenosis, vasodilation induced by pharmacologic stress, provokes a subendocardial underperfusion with a relative epicardial overperfusion which is translated into an impairment of function (echocardiographic dyssynergy) and perfusion (reversible defect at scintigraphy). Medical therapy at time of testing re-equilibrates the imbalance between subendocardial and subepicardial layers, but it affects only function.

tions (beta-blockers and/or calcium antagonists and/or nitrates). The same reduction of dipyridamole test sensitivity is obtained with monotherapy with beta-blockers at 


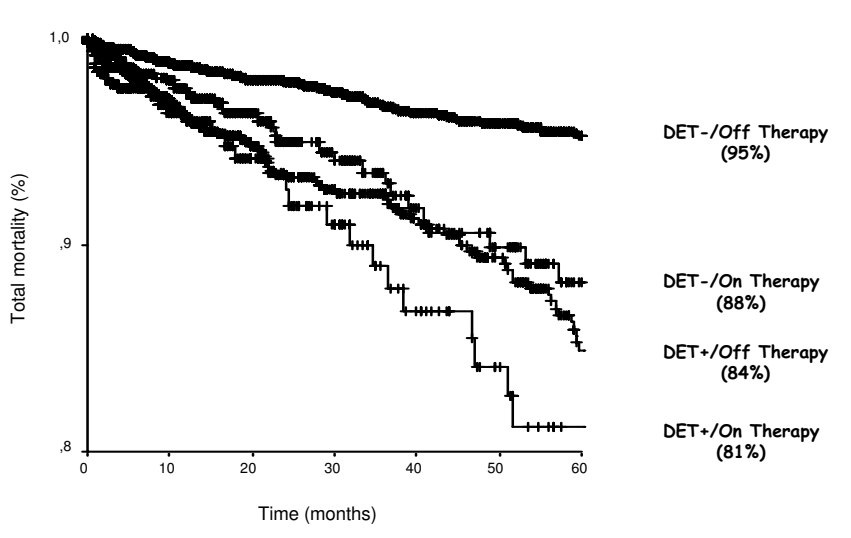

Figure 8

Kaplan-Meier survival curves (considering total mortality as an endpoint) in patients stratified according to presence $(\mathrm{DET}+)$ or absence (DET -) of myocardial ischemia at pharmacological stress echocardiography on and off antianginal medical therapy. The best survival is observed in patients with no inducible ischemia off therapy; the worst survival in patients with inducible ischemia on therapy (Positive DET vs. Negative DET off antianginal medical therapy, $p<0.000$; Positive DET vs. Negative DET on antianginal medical therapy, $P$ $<0.074$ ) (Modified from 3I).

time of testing (100\% off therapy vs. $38 \%$ on therapy) $[22,23]$. (Fig. 4). Interestingly, the positive effects of betablockers on dipyridamole stress are largely independent of the effect on heart rate, possibly involving a direct antisteal effect [21-23]. Angiotensin-converting enzyme inhibitors have no effect on dipyridamole stress echocardiography results [24]. The sensitivity of dobutamine is heavily affected by concomitant beta-blocker therapy. Beta-blockers effect a rightward shift in the dose-response curve to dobutamine and sharply lower test sensitivity, unless atropine is used [25]. (Fig. 5). Calcium antagonists and/or nitrates only mildly reduce dobutamine stress sensitivity ( $100 \%$ off therapy vs. $88 \%$ on therapy, $\mathrm{p}=\mathrm{ns}$ ) (Fig. 6). Non-beta-blocker antianginal therapy reduces the severity of dobutamine-induced ischemia by reducing the value of peak wall motion score index and time of ischemia appearance. However, these changes are not correlated to variations in exercise tolerance [26].

Dipyridamole stress nuclear imaging techniques do not seem to be influenced by anti-ischemic therapy [27]. However, it has been recently demonstrated that acute administration of beta-blockers in patients with known coronary artery disease reduces dipyridamole SPECT sensitivity from $69 \%$ with placebo to $52 \%(\mathrm{p}=0.039)$ with 10 or $20 \mathrm{mg}$ of metoprolol in a per-vessel analysis, but not overall sensitivity [28]. The reason for this difference between stress echocardiography and nuclear imaging is likely to be related to the different markers of ischemia, i.e. wall motion abnormalities vs. perfusion, in the face of the same pathophysiologic mechanism of ischemia: the reduction of coronary reserve. In fact, in the presence of a coronary stenosis, during stress, flow remains elevated in the subepicardial layer but falls in the subepicardium. This selective stress-induced hypoperfusion is important for stress echocardiography, since the regional systolic thickening is linearly and closely related to subendocardial perfusion and only loosely related to subepicardial perfusion [29,30]. (Fig. 7).

\section{Prognostic implications of anti-ischemic therapy during stress testing}

The protective effect of anti-ischemic therapy on inducible myocardial ischemia might exert a powerful impact on prognosis. From the EPIC-EDIC Data bank, it has been analyzed the prognostic impact of antianginal therapy at time of testing in 7333 patients with suspected or known coronary artery disease undergoing pharmacologic stress echocardiography with either dipyridamole or dobutamine. The results show that a positive test on medical therapy is an additional marker of ischemia severity at stress testing whereas a negative test on medical therapy is less prognostically benign, being a false negative result [31]. (Fig. 8). No prognostic difference was found among the various forms of anti-ischemic drugs at time of testing, but the presence per se of antinaginal therapy at time of testing is an independent predictor of death. It is worth noting that in the study only a very low percentage of patients was taking beta-blockers: if on one side this aspect represent a clear lack of adherence to recommendations [13]., on the other it is an observed pattern of prescription in our data base, which simply reflected the clinical practice and the lack of a universally accepted policy of testing regarding concomitant therapy [32,33]. Marwick et al. [34]. have demonstrated a protective effect on mortality of beta-blocker therapy in patients with a negative exercise echocardiography whereas specificity and negative predictive value is increased for the prediction of cardiac events (cardiac death, myocardial infarction and unstable angina) during exercise scintigraphy in patients evaluated off medical therapy at time of testing [35].

The clinical implications of these results are far-reaching. Inducible myocardial ischemia during pharmacological stress testing on medical therapy identifies the subset of patients at highest risk of death. On these patients an aggressive approach has to be undertaken in order to change the natural history of coronary artery disease. On the far opposite end the incidence of death in patients with a negative pharmacologic test off therapy is so low 
Table I: Effects of oral therapy on stress testing sensitivity

\begin{tabular}{lccc}
\hline & Exercise & $\begin{array}{c}\text { STRESS } \\
\text { Dipyridamole }\end{array}$ & Dobutamine \\
\hline Beta-blockers & $\downarrow$ & $\downarrow$ & $\downarrow \downarrow$ \\
Calcium channel blockers & $\downarrow$ & $\downarrow$ & $\downarrow \leftrightarrow$ \\
Nitrates & $\downarrow$ & $\downarrow$ & $\downarrow \leftrightarrow$ \\
ACE-inhibitors & $\leftrightarrow$ & $\leftrightarrow$ & $\leftrightarrow$ \\
Aminophylline & $\downarrow \leftrightarrow$ & $\downarrow \downarrow$ & $\leftrightarrow$ \\
\hline
\end{tabular}

ACE, angiotensin-converting enzyme; $\downarrow$, decreased sensitivity; $\downarrow \downarrow$ markedly decreased sensitivity; $\leftrightarrow$, no effect on sensitivity; $\downarrow \leftrightarrow$, mild decrease in sensitivity.

that no intervention could lower the spontaneous rate of death any further. At intermediate risk are those patients with a negative test on medical therapy or with a positive test off medical therapy. Different clinical scenarios can be foreseen on the basis of the present results: 1) A negative test on medical therapy might represent a false negative result, therefore it is advisable to repeat the test off therapy in order to assess the real ischemic burden through the conventional stress echocardiographic parameters [36,37]. - i.e. number of ischemic segments, severity of induced dysfunction, (both expressed by peak wall motion score index), pharmacologic load and time of onset of ischemia. This is in line with the recommendations of the American Heart Association in patients with stable angina [13].; 2) In the case of a positive test off medical therapy, the effect of therapy can be assessed with the advantage of using an objective, primary ischemic end point such as changes in wall motion during stress.

\section{Conclusions}

Patients may be undergoing various forms of antianginal therapy at the time of testing, both an advantage and a disadvantage for stress echocardiography testing. The disadvantage is that antianginal therapy reduces sensitivity, since stress-induced wall motion abnormalities are caused by the development of obligatory myocardial ischemia. The advantage is that the effect of therapy can be assessed using an objective, primary ischemic end-point such as changes in stress-induced wall motion abnormalities. The presence of ischemia can be titrated on the basis of the ischemic-free stress time and the extent and severity of the induced dyssynergy. The various forms of stress are differently affected by various forms of therapy. In patients with known or suspected coronary artery disease, ongoing anti-ischemic therapy at the time of testing heavily modulates the prognostic value of pharmacological stress echo. In presence of concomitant anti-ischemic therapy, a positive test is more prognostically malignant and a negative test less prognostically benign. However, the decision to remove a patient from beta-blocker therapy for stress testing should be made on an individual basis and should be done carefully to avoid a potential hemodynamic rebound effect, which can lead to accelerated angina or hypertension [38]. No major side effects were recognized when medical therapy was withdrawn in large series of consecutive patients undergoing pharmacologic stress echocardiography [39]. In practical terms, when a test is performed for diagnostic purposes it should be done off medical therapy in order to avoid the influence of medical therapy (in case of hypertensive patients it is possible to prescribe ACE-inhibitors or Angiotensin II receptor blockers that do not exert any protective effect on myocardial ischemia). In patients with known coronary artery disease the decision to suspend medical therapy should be taken on an individual basis in view also of the fact that pharmacologic stress echocardiography is a versatile tool that can assess medical therapy efficacy in the long term prognosis [31].

\section{References}

I. Picano E: Pathogenetic mechanisms of stress. In: Stress echocardiography 4th edition. Edited by: Picano E. Heidelberg, Springer Verlag; 2003:75-90.

2. Ross J Jr: Factors regulating the oxygen consumptionof the heart. In: Changing concepts in cardiovascular disease Edited by: Russek HI, Zoham ML. Baltimore, Williams and Wilkins; 1972.

3. Picano E, Simonetti I, Carpeggiani C, Lattanzi F, Macerata A, Trivella MG, Marzilli M, L'Abbate A: Regional and global biventricular function during dipyridamole stress testing. Am J Cardiol 1989, 63:429-432.

4. Beleslin BD, Ostojic M, Stepanovic J, Djordjevic-Dikic A, Stojkovic S, Nedeljkovic M, Stankovic G, Petrasinovic Z, Gojkovic L, VasiljevicPokrajcic Z: Stress echocardiography in the detection of myocardial ischemia. Head-to-head comparison of exercise, dobutamine, and dipyridamole tests. Circulation 1994, 90: I I 68- I I 76.

5. Picano E: Dipyridamole in myocardial ischemia: Good Samaritan or Terminator? Int J Cardiol 2002, 83:215-216.

6. McNeill AJ, Fioretti PM, el-Said SM, Salustri A, Forster T, Roelandt JR: Enhanced sensitivity for detection of coronary artery disease by addition of atropine to dobutamine stress echocardiography. Am J Cardiol 1992, 70:4I-46.

7. Picano E, Pingitore A, Conti U, Kozakova M, Boem A, Cabani E, Ciuti $M$, Distante A, L'Abbate A: Enhanced sensitivity for detection of coronary artery disease by addition of atropine to dipyridamole echocardiography. Eur Heart J 1993, 14:12 16-1222.

8. Picano E: Dipyridamole echocardiography test: historical background and physiologic basis. Eur Heart J 1989, 10:365-376.

9. Frishman $\mathrm{WH}$ : Multifactorial actions of beta-adrenergic blocking drugs in ischaemic heart disease: current concepts. Circulation 1989, 67:1-II. 
10. Matsusaki M, Patritti J, Tajimi T, Miller M, Kemper WS, Ross J: Effects of beta-blockade on regional myocardial flow and function during exercise. Am J Physiol 1984, 247:H52-60.

II. Hintze TH, Vatner SF: Dipyridamole dilates large coronary arteries in conscious dogs. Circulation 1983, 68: | 32 |-1327.

12. Schwartz JS, Bache RJ: Pharmacologic vasodilators in the coronary circulation. Circulation 1984, 69:80I-8I4.

13. Gibbons RJ, Abrams J, Chatterjee K, Daley J, Deedwania PC, Douglas SJ, Ferguson BT, Fihn SD, Fraker TD, Gardin JM, O'Rourke RA, Patsernak RC, Willimas SV: ACCIAHA 2002 guideline update for the management of patients with chronic stable angina: a report of the American College of Cardiology/American Heart Association Task Force on Practice Guidelines (Committee to Update the 1999 Guidelines for the management of Patients with Chronic Stable Angina. Circulation 2003, 107:149-158.

14. Iskandrian AS, Heo J, Kong B, Lyons E: Effect of exercise level on the ability of thallium-20 I tomographic imaging in detecting coronary artery disease: analysis of $46 \mathrm{I}$ patients. J Am Coll Cardiol 1989, 14:1477-86.

15. Steele P, Sklar J, Kirch D, Vogel R, Rhodes CA: Thallium-20 I myocardial imaging during maximal and submaximal exercise: comparison of submaximal exercise with propranolol. Am Heart J 1983, 106: I353-7.

16. Hockings B, Saltissi S, Croft DN, Webb-Peploe MM: Effect of beta adrenergic blockade on thallium-20I myocardial perfusion imaging. Br Heart J 1 983, 49:83-9.

17. Martin G], Henkin RE, Scanlon PJ: Beta blockers and the sensitivity of the thallium treadmill test. Chest 1987, 92:486-7.

18. Zacca NM, Verani MS, Chahine RA, Miller RR: Effect of nifedipine on exercise-induced left ventricular dysfunction and myocardial hypoperfusion in stable angina. Am J Cardiol I 982, 50:689-95.

19. Marwick TH, Nemec JJ, Pashkow FJ, Stewart WJ, Salcedo EE: Accuracy and limitations of exercise echocardiography in a routine clinical setting. J Am Coll Cardiol 1992, 19:74-8I.

20. San Roman JA, Vilacosta I, Castillo JA, Rollan MJ, Peral V, SanchezHarguindey L, Fernandez-Aviles F: Dipyridamole and dobutamine-atropine stress echocardiography in the diagnosis of coronary artery disease. Comparison with exercise stress test, analysis of agreement, and impact of antianginal treatment. Chest 1996, I 1 0:1248-1254.

21. Lattanzi F, Picano E, Bolognese L, Piccinino C, Sarasso G, Orlandini A, L'Abbate A: Inhibition of dipyridamole-induced ischemia by antianginal therapy in humans. Correlation with exercise electrocardiography. Circulation |99|, 83:| 256-| 262.

22. Ferrara N, Coltorti $F$, Leosco D, Sederino S, Abete P, Caccese $P$, Landing P, Longobardi G, Verde R, Rengo F: Protective effect of beta-blockade on dipyridamole-induced myocardial ischemia. Role of heart rate. Eur Heart J 1995, 16:903-908.

23. Ferrara N, Longobardi G, Nicolino A, Acanfora D, Odierna L, Furgi G, Rossi M, Leosco D, Rengo F: Effect of beta-adrenoceptor blockade on dipyridamole-induced myocardial asynergies in coronary artery disease. Am J Cardiol 1992, 70:724-727.

24. Longobardi G, Ferrara N, Leosco D, Nicolino A, Acanfora D, Furgi G, Guerra N, Papa A, Abete P, Rengo F: Failure of protective effect of captopril and enalapril on exercise and dipyirdamoleinduced ischemia. Am J Cardiol 1995, 76:255-258.

25. Fioretti PM, Poldermans D, Salustri A, Forster T, Bellotti P, Boersma E, McNeill AJ, el-Said ES, Roelandt JR: Atropine increases the accuracy of dobutamine stress echocardiography in patients taking beta-blockers. Eur Heart ] I 994, I 5:355-360.

26. Dodi C, Pingitore A, Sicari R, Bruno G, Cordovil A, Picano E: Effects of antianginal therapy with calcium antagonists and nitrates on dobutamine atropine-stress echocardiography. Comparison with exercise electrocardiography. Eur Heart J 1997, 18:242-247.

27. Beller GA, Gibson RS: Sensitivity and specificity and prognostic significance of non-invasive testing for occult or known coronary disease. Prog Cardiovasc Dis 1987, 29:24I-270.

28. Taillefer R, Ahlberg AW, Masood Y, White CM, Lamargese I, Mather JF, McGill CC, Heller GV: Acute beta-blockade reduces the extent and severity of myocardial perfusion defects with dipyridamole Tc-99m sestamibi Spect imaging. I Am Coll Cardiol 2003, 42: 1475-83.

29. Ross J Jr: Mechanisms of regional ischemia and antianginal drug action during exercise. Prog Cardiovasc Dis 1989, 3 I:455-466.
30. Gallagher KP, Matsuzaki M, Koziol JA, Kemper WS, Ross J Jr: Regional myocardial perfusion and wall thickening during ischemia in conscious dogs. Am J Physiol 1984, 247:H727-738.

3I. Sicari R, Cortigiani L, Bigi R, Landi P, Raciti M, Picano E, on behalf of the Echo-Persantine International Cooperative (EPIC) Study Group and Echo-Dobutamine International Cooperative (EDIC) Study Group: The Prognostic value of pharmacological stress echo is affected by concomitant anti-ischemic therapy at the time of testing. Circulation 2004, 109:2428-2431.

32. Wang TJ, Stafford RS: National patterns and predictors of betablocker use in patients with coronary artery disease. Arch Intern Med 1998, I 58:1901-6.

33. Freemantle N, Cleland J, Young P, Mason J, Harrison J: Beta-blockade after myocardial infarction: systematic review and meta regression analysis. $B M]$ I999, 3 I 8: 1730-7.

34. Marwick TH, Case C, Sawada S, Rimmerman C, Brenneman P, Kovacs $R$, Short L, Lauer M: Prediction of mortality by exercise echocardiography. Circulation 200I, 103:2566-257I.

35. Burns RJ, Kruzyk GC, Armitage DL, Druck MN: Effect of antianginal medications on the prognostic value of exercise thallium scintigraphy. Can J Cardiol I 989, 5:29-32.

36. Sicari R, Pasanisi E, Venneri L, Landi P, Cortigiani L, Picano E: Stress echo results predict mortality: a large scale multicenter prospective international study. J Am Coll Cardiol 2003, 41:589-95.

37. Picano E: Stress echocardiography: a historical perspective. Special article. Am J Med 2003, I | 4: | 26-30.

38. Picano E: Prognosis. In: Stress echocardiography 4th edition. Edited by: Picano E. Heidelberg, Springer Verlag; 2003:239-252.

39. Cortigiani L, Zanetti L, Bigi R, Desideri A, Fiorentini C, Nannini E: Safety and feasibility of dobutamine and dipyridamole stress echocardiography in hypertensive patients. J Hypertens 2002, 20:| $423-9$.
Publish with BioMed Central and every scientist can read your work free of charge

"BioMed Central will be the most significant development for disseminating the results of biomedical research in our lifetime. "

Sir Paul Nurse, Cancer Research UK

Your research papers will be:

- available free of charge to the entire biomedical community

- peer reviewed and published immediately upon acceptance

- cited in PubMed and archived on PubMed Central

- yours - you keep the copyright

Submit your manuscript here:

http://www.biomedcentral.com/info/publishing_adv.asp 